\title{
Novel Interpositional Vein Grafting for Pedicle Extension of Island Pedicle Flaps
}

\author{
Shuhei Yoshida, MD ${ }^{1}$ Isao Koshima, MD ${ }^{1}$ Shogo Nagamatsu, MD ${ }^{2}$ Kazunori Yokota, MD $^{2}$ \\ Shuji Yamashita, $\mathrm{MD}^{3}$ Mitsunobu Harima, MD ${ }^{3}$ Kensuke Tashiro, MD
}

\author{
${ }^{1}$ International Center for Lymphedema (ICL), Hiroshima University \\ Hospital, Hiroshima, Japan \\ ${ }^{2}$ Department of Plastic and Reconstructive Surgery, Hiroshima \\ University Hospital, Hiroshima, Japan \\ ${ }^{3}$ Department of Plastic and Reconstructive Surgery, Graduate School \\ of Medicine, The University of Tokyo, Tokyo, Japan \\ ${ }^{4}$ Department of Plastic and Reconstructive Surgery, Jichi Medical \\ University, Tochigi, Japan
}

J Reconstr Microsurg Open 2018;3:e50-e54.
Address for correspondence Shuhei Yoshida, MD, International Center for Lymphedema (ICL), Hiroshima University Hospital, 1-2-3, Kasumi, Minami-ku, Hiroshima City, 734-8551 Japan (e-mail: syuheiyoshida44@gmail.com).

\begin{abstract}
Keywords

- vein grafting

- free flaps

- island pedicle flaps

Use of island pedicle flaps is often problematic of their limited reach. In such cases, free flaps are very useful for reconstruction. However, unless the recipient vessels around the area to be reconstructed have a good circulation, use of a free flap becomes difficult. Vein grafts and even arteriovenous loops have been used to lengthen the pedicle between a free flap and the recipient vessels. ${ }^{1-3}$ However, it would be easier if there was the option of making the pedicle of the island flap as long as needed. Here, we report on the use of an
\end{abstract}

Background Island pedicle flaps often have the problem of limited reach. In such cases, free flaps are useful for reconstruction but often have the issue of unavailability of suitable recipient vessels. Therefore, it would be helpful if the pedicle of an island flap could be extended as far as necessary.

Methods Here, we describe the use of interpositional vein grafts to extend island pedicle flaps for the reconstruction of an ischemic above-knee amputation stump in one case and to seal an intractable fistula on the buttock after radiation therapy in another case. In the patient with the ischemic stump, a deep inferior epigastric perforator flap was extended by $6 \mathrm{~cm}$ using the great saphenous vein harvested from the contralateral side, allowing successful coverage of the stump. In the patient with an intractable fistula on the buttock, a thoracodorsal artery and vein graft that was extended by $25 \mathrm{~cm}$ using the cephalic vein harvested from the right forearm to upper arm allowed successful sealing of the fistula.

Results Circulation was satisfactory in both cases and both flaps survived. The operative procedure was straightforward.

Conclusion Interpositional vein grafts may be a feasible option for the extension of island pedicle flaps to include the features of an island pedicle flap and a free flap. interpositional vein graft to extend an island pedicle flap for the reconstruction of an ischemic above-knee amputation stump in one case and to seal an intractable fistula on the buttock after radiation therapy in another.

\section{Case 1}

A 90-year-old woman presented with a necrotic stump after undergoing a left above-knee amputation because of received

June 6, 2018

accepted

July 25,2018
DOI https://doi.org/

$10.1055 / \mathrm{s}-0038-1669452$.

ISSN 2377-0813.
Copyright $\odot 2018$ by Thieme Medical

Publishers, Inc., 333 Seventh Avenue, New York, NY 10001, USA. Tel: +1(212) 584-4662.
License terms

(2) (1) $\Theta \circledast$ 

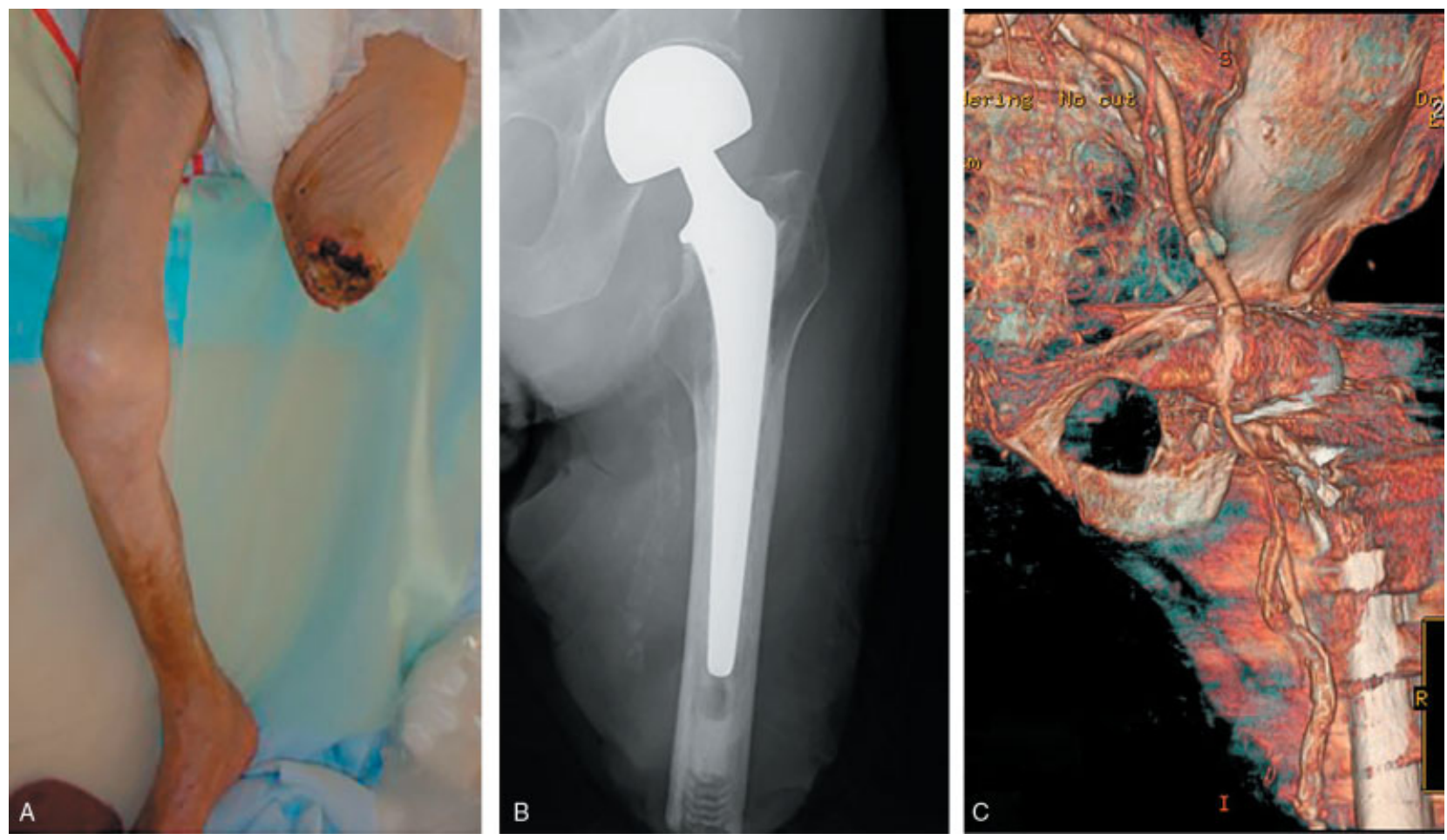

Fig. 1 (A) A 90-year-old woman with a necrotic stump because of ischemic necrosis. (B) The patient had undergone a left total hip replacement. (C) The femoral artery appeared to be extensively calcified and stenotic.

ischemic necrosis caused by arteriosclerotic obstruction ( - Fig. 1A). Fifteen years earlier, she had undergone a left total hip replacement ( $\mathbf{- F i g . 1 B}$ ). She was referred to our hospital for the coverage of the soft tissue defect.

The femoral artery appeared to be extensively calcified and stenotic on a multidetector computed tomography angiogram; however, the central posterior arteries derived from the external iliac artery appeared to be less diseased (-Fig. 1C). Hip disarticulation would have been indicated if we had chosen to close the ulcer by shortening the stump. However, the patient and her family hoped to retain the length of the affected lower limb. Given that the recipient vessels were either outside the affected zone of the calcified and stenotic areas, the decision was made to cover the stump using a left deep inferior epigastric perforator (DIEP) flap.

The DIEP flap was raised after debridement of the stump. The pedicle of the flap was dissected as far as possible in the proximal direction, but the flap did not reach the end of the stump ( - Fig. 2A). The deep inferior epigastric artery and collateral vein were extended by $6 \mathrm{~cm}$ by interposing venous grafts taken from a segment of the right great saphenous vein (-Fig. 2B). The exposed stump was covered with the skin paddle. The postoperative course was uneventful and the entire skin paddle survived (-Fig. $\mathbf{2 C}$ ).

\section{Case 2}

An 86-year-old woman presented to our institution with an intractable fistula that had first developed on her left buttock 30 years earlier after undergoing radiation therapy for uterine cancer ( $\mathbf{F i g} . \mathbf{3 A}$ ). The inguinal region, superior posterior iliac spine, and both iliac crests were widely covered with scar tissue (-Fig. 3B, C). The subcutaneous tissue around the fistula was found to be extensively calcified on computed tomography images ( - Fig. 3D). Diagnosis of a radiation ulcer was straightforward. Severe calcifications were distributed along the iliac and femoral arteries and it was evident that a femoropopliteal bypass procedure had been performed ( - Fig. $\mathbf{3 E}$ ). The circulation in the area surrounding the femoral artery and buttocks and supplying the flap was unreliable. A fistulectomy involving the surrounding calcified tissue was performed. The resulting defect was $15 \mathrm{~cm} \times 12 \mathrm{~cm}$ in size and bled less easily. The gluteus maximus muscle was exposed. A $15 \mathrm{~cm} \times 12 \mathrm{~cm}$ latissimus dorsi muscle flap was raised and a $50-\mathrm{cm}$ length of cephalic vein was harvested from her right forearm and upper arm. After dividing the harvested length of vein into two parts, one length was inserted into the thoracodorsal artery and the other into the corresponding vein ( - Fig. 4A, B). After anastomosis, the latissimus dorsi muscle flap was well perfused. The flap survived and the wound healed (-Fig. $\mathbf{4 C}$ ).

\section{Discussion}

Although a vein graft makes it possible to extend the transplant range of an island pedicle flap, interpositional vein grafts may be expected to increase the risk of failure. However, there is some evidence suggesting that the success rate for vein-grafted free flaps is not different from that 

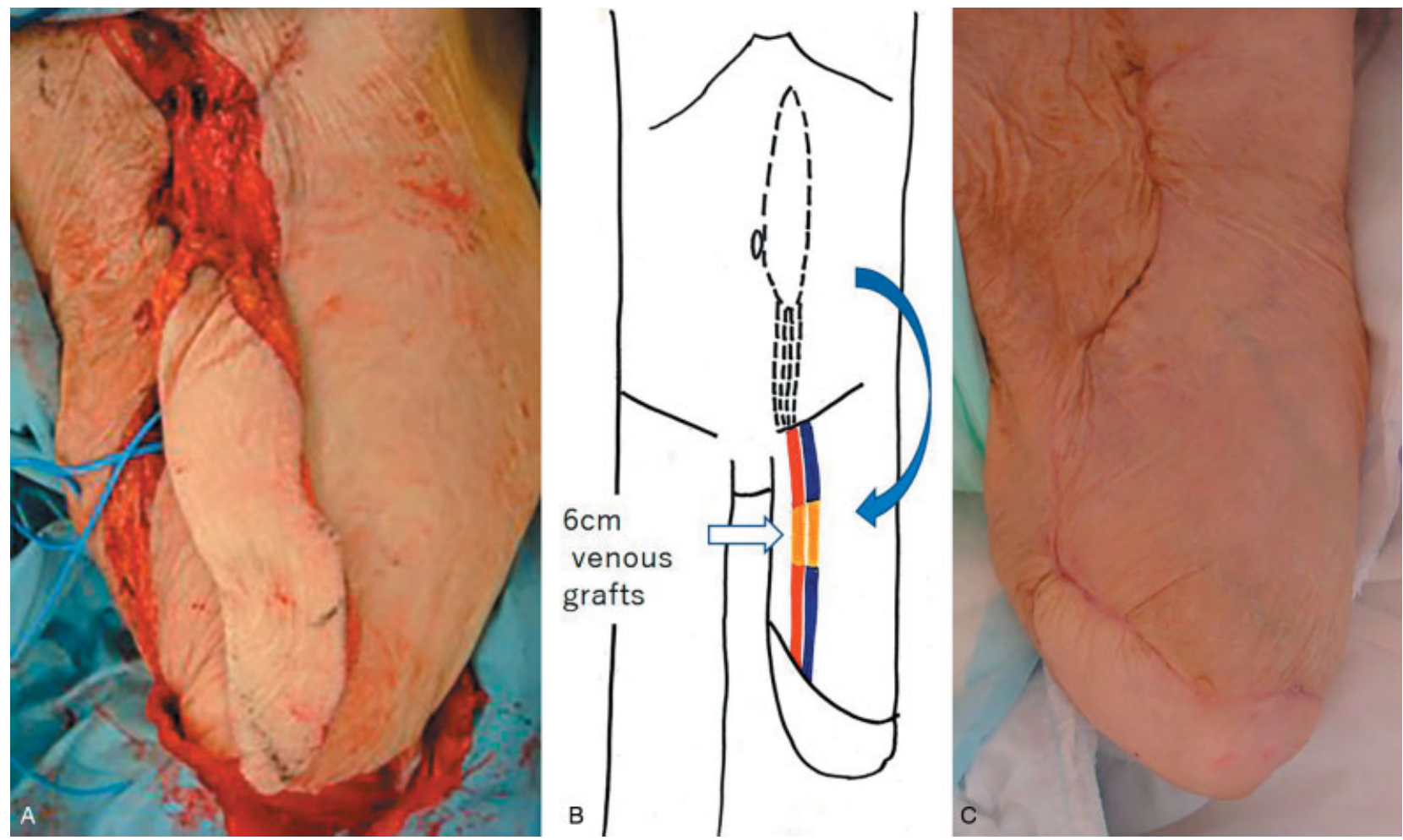

Fig. 2 (A) The flap did not reach the end of the stump. (B) The pedicle was extended by $6 \mathrm{~cm}$ by interposing venous grafts. (C) The postoperative course was uneventful and the entire skin paddle survived.
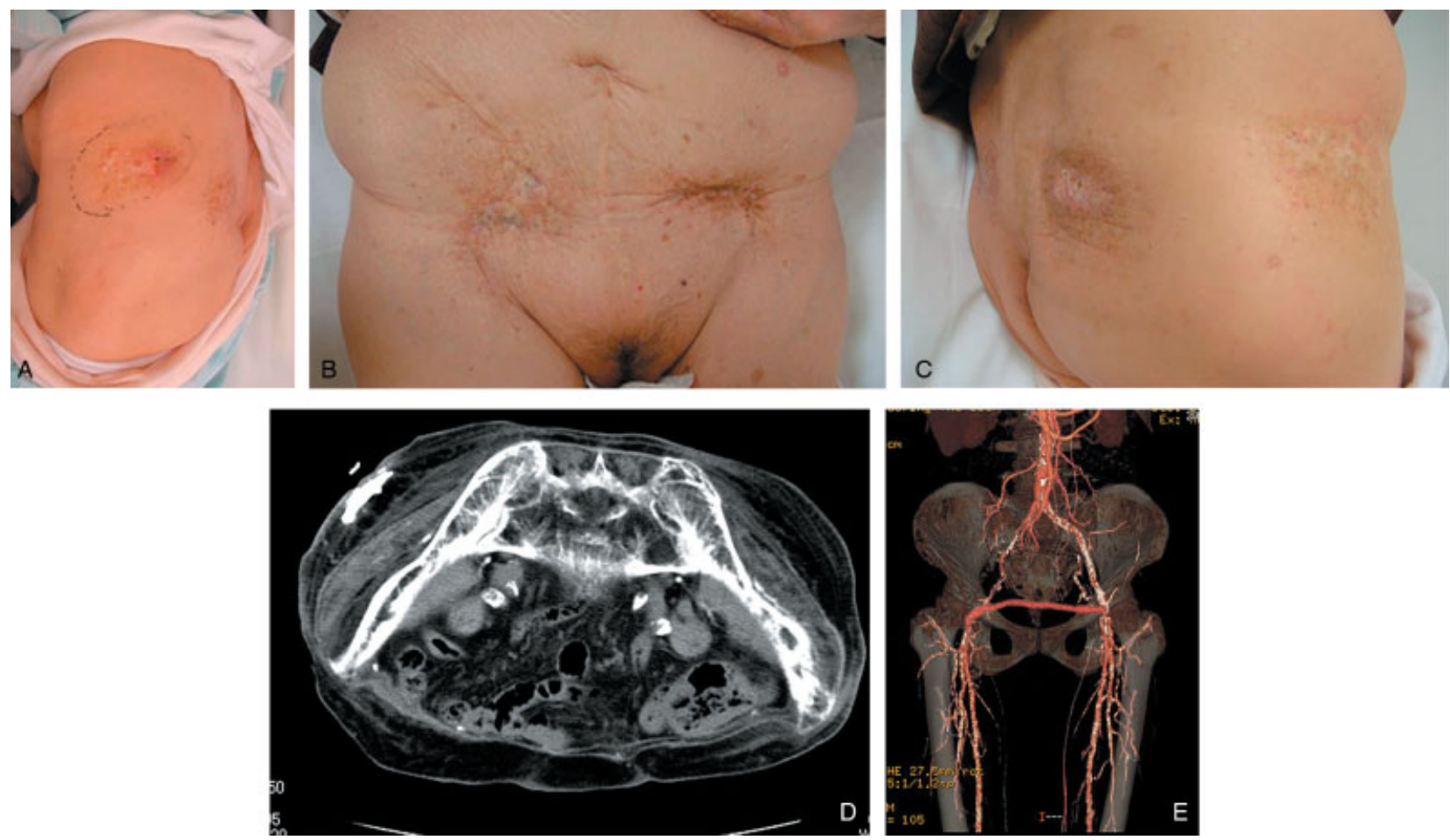

Fig. 3 (A) An 86-year-old woman with an intractable fistula because of radiation therapy. (B, C) The inguinal region, superior posterior iliac spine, and both iliac crests were widely covered with scar tissue. (D) The subcutaneous tissue around the fistula was found to be extensively calcified. (E) Severe calcifications along the iliac and femoral arteries. A femoropopliteal bypass procedure had been performed. 

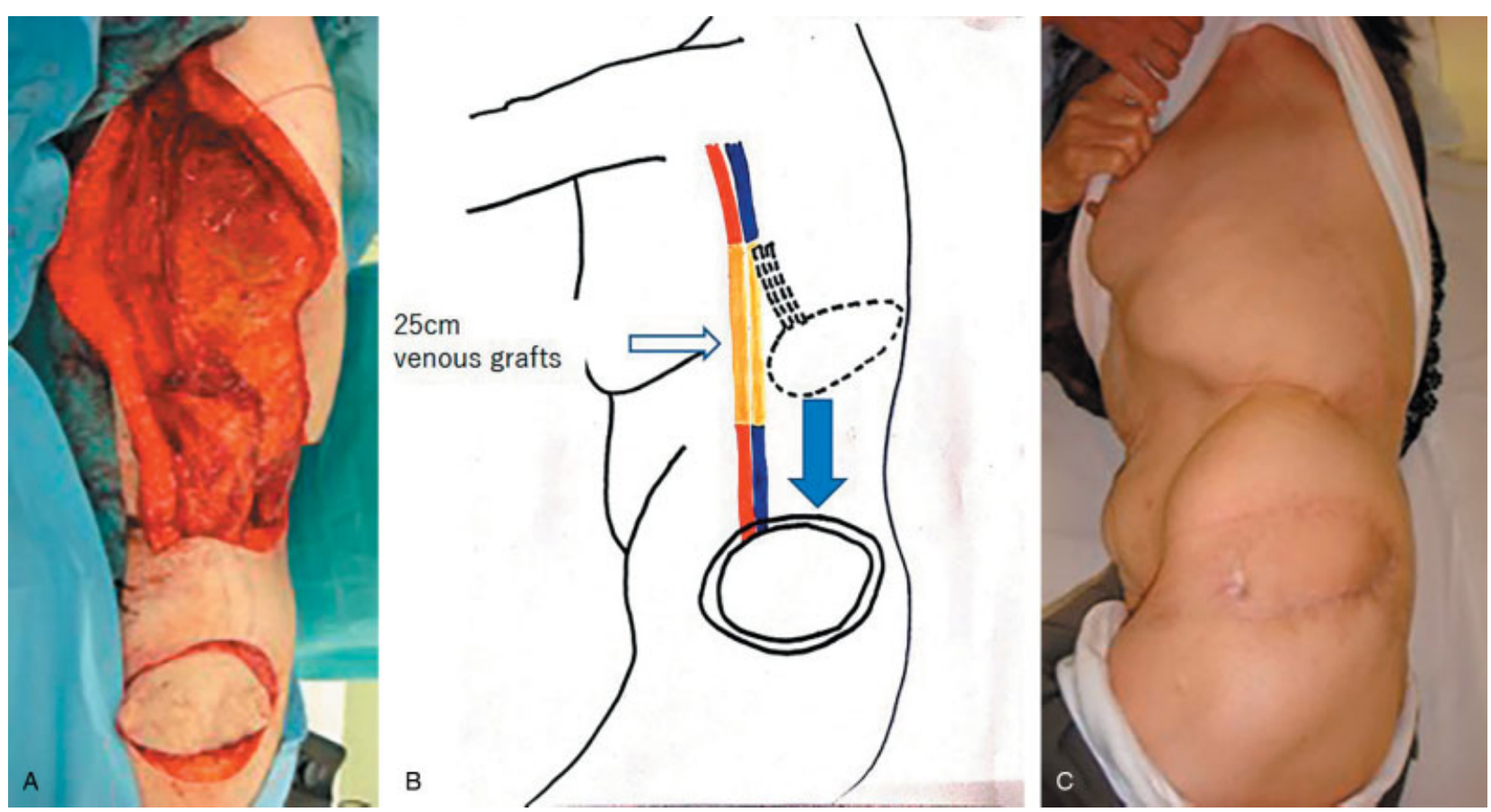

Fig. 4 (A, B) Two parts of vein were inserted into the thoracodorsal artery and the corresponding vein. (C) The flap survived and the wound healed.

for simple free flap transfers. ${ }^{4}$ Several clinical reports have cautioned against use of interposition vein grafts in free tissue transfers because of high complication rates. ${ }^{5-7}$ Technical factors, such as excessive surgical trauma and double anastomoses disrupting the normal laminar flow, were thought to increase the thrombogenic response and eventually cause thrombosis in these vein grafts. However, the results of well-controlled experiments did not support the technical risk hypothesis and most studies have concluded that vein grafting is not a high-risk procedure when the surgical management is optimal. ${ }^{8-11}$ Use of interpositional vein grafts for the extension of island pedicle flaps provides evidence of this theory, in that insertion of a vein graft into the pedicle does not seem to increase the risk of a thrombogenic response via the anastomosis. The advantages of this method are that the extent of vascular dissection at the recipient and donor sites is similar; there is no need to consider the circulation at the recipient site; and the superficial veins are dissected more easily than the recipient vessels.

The main disadvantage of using this method is that the exact amount of extension achieved cannot be accurately predicted and may differ from flap to flap. However, in our patient, there were no problems attaching a $25-\mathrm{cm}$ vein graft to a thoracodorsal artery flap, as has been reported previously. ${ }^{12}$ Another report suggests that it is even possible to use a vein graft that is $46 \mathrm{~cm}$ in length. ${ }^{13}$ Taking these reports into account, adaptation of an interpositional vein graft for the extension of an island pedicle flap is acceptable because of the limited reach of island pedicle flaps and the problem of availability of recipient vessels when using free flaps.

\section{Conclusion}

Interpositional vein graft for the extension of an island pedicle flap is one of options if there is the limited reach of island pedicle flaps and the problem of availability of recipient vessels when using free flaps.

\section{Funding}

None.

\section{Conflict of Interest}

None.

\section{References}

1 Lin CH, Mardini S, Lin YT, Yeh JT, Wei FC, Chen HC. Sixty-five clinical cases of free tissue transfer using long arteriovenous fistulas or vein grafts. J Trauma 2004;56(05):1107-1117

2 Hallock GG. The interposition arteriovenous loop revisited. J Reconstr Microsurg 1988;4(02):155-159

3 Angel MF, Chang B, Clark N, Wong L, Ringelman P, Manson PN. Further clinical use of the interposition arteriovenous loop graft in free tissue transfers. Microsurgery 1993;14(08):479-481

4 Bayramiçli M, Tetik C, Sönmez A, Gürünlüoğlu R, Baltaci F. Reliability of primary vein grafts in lower extremity free tissue transfers. Ann Plast Surg 2002;48(01):21-29

5 Whitney TM, Buncke HJ, Lineaweaver WC, Alpert BS. Multiple microvascular transplants: a preliminary report of simultaneous versus sequential reconstruction. Ann Plast Surg 1989;22(05):391-404

6 Khouri RK, Shaw WW. Reconstruction of the lower extremity with microvascular free flaps: a 10-year experience with 304 consecutive cases. J Trauma 1989;29(08):1086-1094

7 Miller MJ, Schusterman MA, Reece GP, Kroll SS. Interposition vein grafting in head and neck reconstructive microsurgery. J Reconstr Microsurg 1993;9(03):245-251 
e54 Interpositional Vein Grafting for Pedicle Extension of Island Pedicle Flaps Yoshida et al.

8 Zhang F, Oliva A, Kao SD, Newlin L, Buncke HJ. Microvascular vein-graft patency in the rat model. J Reconstr Microsurg 1994;10(04):223-227

9 Zhang F, Oliva A, Kao SD, Newlin L, Buncke HJ. Microvascular vein grafts in the rat cutaneous free-flap model. J Reconstr Microsurg 1994;10(04):229-233

10 Cheng HT, Lin FY, Chang SC. Evidence-based analysis of vein graft interposition in head and neck free flap reconstruction. Plast Reconstr Surg 2012;129(05):853e-854e
11 Furr MC, Cannady S, Wax MK. Interposition vein grafts in microvascular head and neck reconstruction. Laryngoscope 2011;121 (04):707-711

12 Nahai F, Hester TR, Jurkiewicz MJ. Microsurgical replantation of the scalp. J Trauma 1985;25(09):897-902

13 Fudem GM, Marble KR. Latissimus dorsi free flap for sacral wound closure: the world's longest vein grafts for free tissue transfer. Microsurgery 1996;17(08):449-451 